\title{
Editorial Comment: Management of post TURP strictures
}

Kulkarni SB ', Joglekar O ', Alkandari M ', Joshi PM ${ }^{1}$

${ }^{1}$ Kulkarni Reconstructive Urology Center, 3, Rajpath Society, Opp Vanaz Engineering, Paud Road, Pune, 411038, India

World J Urol. 2019 Apr;37(4):589-594

DOI: $10.1007 / s 00345-018-2498-x$ | ACCESS: $10.1007 /$ s00345-018-2498-x

Luciano A. Favorito ${ }^{1}, 2$

${ }^{1}$ Unidade de Pesquisa Urogenital - Universidade Estadual do Rio de Janeiro - Uerj, Rio de Janeiro, RJ, Brasil; ${ }^{2}$ Serviço de Urologia, Hospital Federal da Lagoa, Rio de Janeiro, RJ, Brasil

\section{COMMENT}

Trans-urethral prostate resection (TURP) is one of the most common urologic surgeries and the urethral stricture is an important complication (1). In the present paper Dr. Kulkarni, in a prospective study with 170 patients shows that bulbar stricture is the most frequent affected area with stricture post TURP (143 patients) and that buccal mucosa graft (BMG) is safe, feasible and with long-term success in these patients that should be strongly considered. The overall success rate of Kulkarni with BMG was 82\% in this paper. Other important presented result is that the Ventral approach is best suited for proximal bulbar strictures close to membranous urethra.

BMG placement can be ventral, dorsal or lateral (2-4). Ventral location provides the advantages of ease of exposure and good vascular supply by avoiding circumferential rotation of the urethra (5) and this paper shows that in post TURP stricture near the membranous urethra this technique is the best option. This is a very important publishing and we would like to congratulate the authors. 


\section{REFERENCES}

1. Payne SR, Fowler S, Mundy AR. Analysis of a 7-year national online audit of the management of open reconstructive urethral surgery in men. BJU Int. 2019 Aug 16. [Epub ahead of print].

2. Prakash G, Singh BP, Sinha RJ, Jhanwar A, Sankhwar S. Is circumferential urethral mobilization an overdo? A prospective outcome analysis of dorsal onlay and dorso - lateral onlay BMGU for anterior urethral strictures. Int Braz J Urol. 2018;44:323-9.

3. Favorito LA, Conte PP, Sobrinho UG, Martins RG, Accioly T. Double inlay plus ventral onlay buccal mucosa graft for simultaneous penile and bulbar urethral stricture. Int Braz J Urol. 2018;44:838-9.

Luciano A. Favorito, MD, PhD

Unidade de Pesquisa Urogenital - Universidade Estadual do Rio de Janeiro - Uerj, Rio de Janeiro, RJ, Brasil

E-mail:lufavorito@yahoo.com.br
4. Alsagheer GA, Fathi A, Abdel-Kader MS, Hasan AM, Mohamed 0, Mahmoud 0, Abolyosr A. Management of long segment anterior urethral stricture $(\geq 8 \mathrm{~cm})$ using buccal mucosal (BM) graft and penile skin (PS) flap: outcome and predictors of failure. Int Braz J Urol. 2018;44:163-71.

5. Barbagli G, Palminteri E, Guazzoni G, Montorsi F, Turini $D$, Lazzeri M. Bulbar urethroplasty using buccal mucosa grafts placed on the ventral, dorsal or lateral surface of the urethra: are results affected by the surgical technique? J Urol. 2005;174:955-7; discussion 957-8.
ARTICLE INFO

iD Luciano A. Favorito

http://orcid.org/0000-0003-1562-6068

Int Braz J Urol. 2020; 46: 126-7 